BULLETIN Bulletin hispanique

HISPANIQUE Université Michel de Montaigne Bordeaux

119-1 | 2017

Autorité et pouvoir dans le théâtre du Siècle d'Or

\title{
Sebastián de Covarrubias como recopilador y transmisor del saber generado durante el Humanismo acerca del arabismo léxico en español
}

\section{Stefan Ruhstaller}

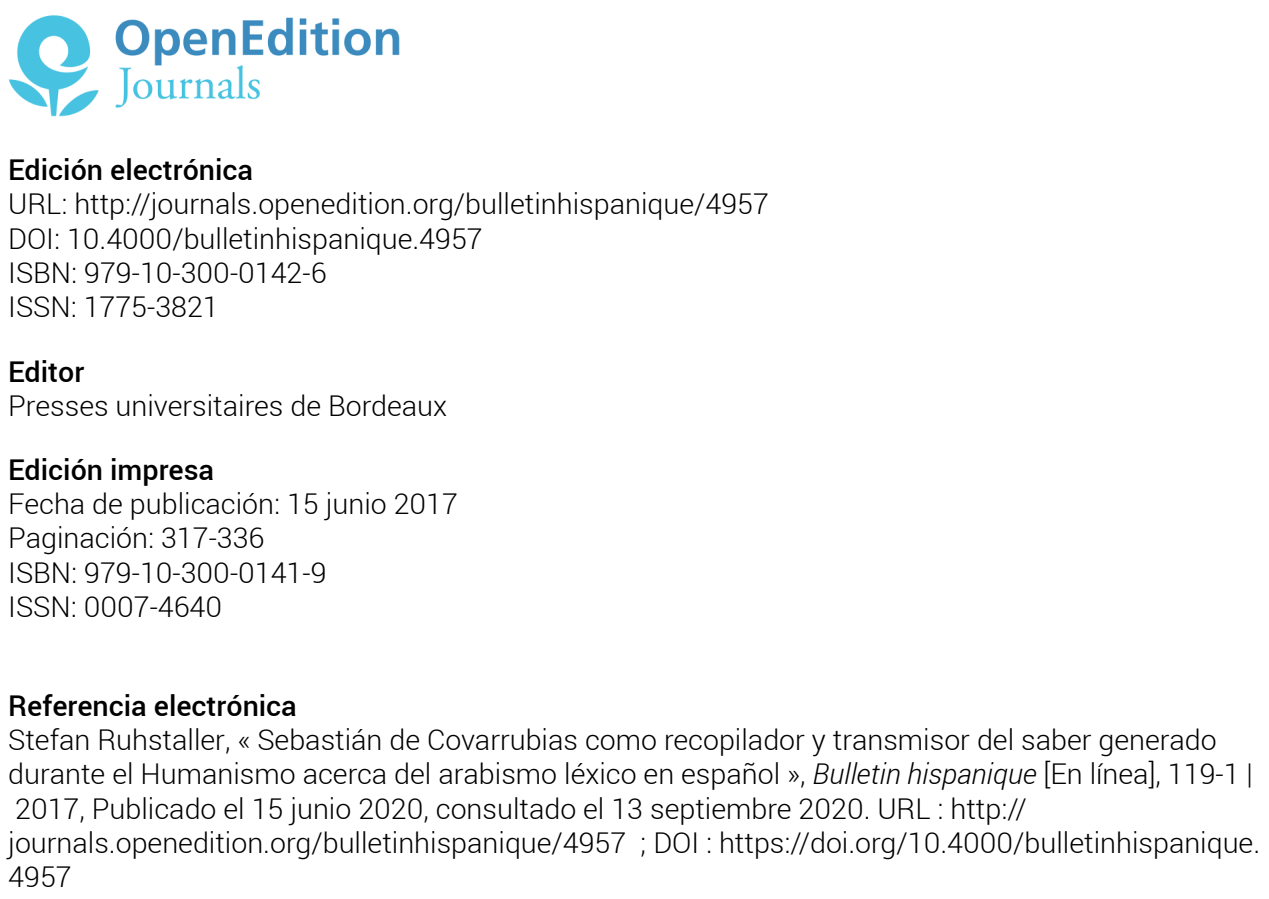

Tous droits réservés 


\title{
Sebastián de Covarrubias como recopilador $\mathrm{y}$ transmisor del saber generado durante el Humanismo acerca del arabismo léxico en español
}

\author{
Stefan Ruhstaller \\ Universidad Pablo de Olavide - Sevilla
}

Une analyse minutieuse des articles du Tesoro que Covarrubias consacre aux arabismes de l'espagnol révèle les critères adoptés par le lexicographe pour traiter les données obtenues à partir de différentes sources, dont les plus importantes d'entre elles inédites. L'étude de sa réception par les auteurs ultérieurs permet de démontrer que Covarrubias a joué un rôle central dans la diffusion du savoir accumulé sur le sujet par les humanistes espagnols.

Mots-clés: lexicographie historique, Sebastián de Covarrubias, arabisme, étymologie.

El análisis minucioso de los artículos del Tesoro de Covarrubias dedicados a los arabismos del español revela los criterios según los cuales el lexicógrafo aprovechó el material que había extraído de diversas fuentes, en su mayoría inéditas. El estudio de su recepción en autores posteriores permite demostrar que Covarrubias desempeñó un papel central en la difusión del saber generado sobre la materia en el humanismo español.

Palabras-claves: lexicografía histórica, Sebastián de Covarrubias, arabismo, etimología.

A careful analysis of the articles dedicated to Spanish lexicon of Arabic origin in the Tesoro de la lengua castellana o española reveals the criteria by which Covarrubias handled the material extracted from different (mainly unpublished) sources. The study of his reception in later authors proves that Covarrubias played a central role in the dissemination of the knowledge generated on the subject in the context of Spanish Humanism.

Keywords: historic lexicography, Sebastián de Covarrubias, Arabic loanwords, etymology. 


\section{INTRODUCCIÓN}

En el desarrollo y la consolidación de las disciplinas es tan importante el papel que desempeñan las personas que transmiten los conocimientos científicos como el desempeñado por quienes los generan de primera mano. De hecho, no pocas veces los criterios -acertados o no- que los difusores aplican a la selección y valoración de la información marcan decisivamente la evolución de la investigación, haciendo que se den a conocer unos autores y otros no, y que prevalezcan, al menos durante un tiempo, unas ideas sobre otras. Este es el caso también del estudio que se llevó a cabo durante varios siglos sobre la materia del elemento árabe presente en la lengua española, pues su trayectoria estuvo marcada por la obra de un erudito que, según reconocía explícitamente, no tenía conocimientos, ni teóricos ni prácticos, del árabe: Sebastián de Covarrubias. Explicar esta aparente paradoja y poner de relieve los méritos del célebre lexicógrafo en esta materia es lo que me propongo en las páginas que siguen.

Al igual que cualquier persona culta de su época (recordemos por ejemplo las palabras de Don Quijote en el capítulo LXVII de la segunda parte de la novela), Covarrubias naturalmente era consciente de la importante impronta que había dejado el árabe en el léxico español. Las etimologías árabes que se exponen a lo largo de su diccionario suman, como ha mostrado un recuento completo de la obra, un total de 628, y su grado de exhaustividad es muy variable. En unos 140 casos la información dada se limita a una escueta adscripción estratigráfica, basada a menudo en la intuición del propio lexicógrafo; en cambio, cuando Covarrubias ofrece datos más concretos casi siempre parte de otras fuentes en cuya solvencia confía en mayor o menor medida. Su contribución al estudio del léxico español de origen árabe no consiste, pues, en la aportación de teorías originales (como sí ocurría con la de autores como Francisco López Tamarid o Diego de Guadix, según pusimos de relieve en Ruhstaller 2013), sino sobre todo en la recopilación de información a partir de textos anteriores y su exposición y valoración en el diccionario. No obstante, dado que dichas fuentes poseen ciertas características muy peculiares, y dado que el Tesoro de la lengua gozó de una recepción muy intensa en siglos posteriores, el papel desempeñado por Covarrubias en la historia de la investigación del léxico español de origen árabe resultó crucial e irreemplazable, como vamos a demostrar.

\section{COVARRUBIAS COMO RECOPILADOR: LAS FUENTES Y SU APROVECHAMIENTO}

\section{Diego de Urrea}

Entre las numerosísimas fuentes aprovechadas en el Tesoro, Diego de Urrea es sin duda una de las más peculiares. A diferencia de las demás, Covarrubias en este caso no extrae su información de una obra propiamente dicha, terminada 
e independiente del Tesoro, sino que la obtiene a través de la consulta ad hoc, directa y personal, a uno de los más prestigiosos expertos en la materia, el intérprete real de árabe, persa y turco y catedrático de árabe en Alcalá de Henares, al que Covarrubias al parecer conocía personalmente ${ }^{1}$. Indudablemente, Urrea le proporcionó su información por escrito con anterioridad a la redacción del Tesoro o al menos a su comienzo, a juzgar por alguna cita literal ${ }^{2}$ y la referencia a diferentes "partes» de un texto que consultaba el lexicógrafo ${ }^{3}$. Además, prueba que Covarrubias se basaba en notas recibidas en un momento previo al acto de redacción el hecho de que la información a veces no le resultara del todo inteligible -s.v. ajorcas, por ejemplo, introduce la información tomada de la fuente matizando: «Diego de Urrea presupone, a lo que entiendo, que...»-, sin que tuviera la posibilidad de pedir una aclaración inmediata al autor. Con todo, a pesar de que el contacto con Urrea no debió de ser constante, fue lo suficientemente duradero como para permitirle hacer una nueva consulta sobre alguna cuestión dudosa en un momento posterior; así, al volver a tratar la voz hanega por segunda vez en el Suplemento, el lexicógrafo nos informa (cf. Crespo 1992: 106): «He consultado nueuamente esta palabra con Diego de Vrrea, y dize traer origen del verbo Arábigo fenege que sinifica ablentar y echar en alto el trigo, y su terminación es fenigetum.»

Urrea atendió la petición de Covarrubias con gran generosidad, pues le proporcionó $192^{4}$ explicaciones etimológicas detalladas y de gran calidad científica, incluso en términos lingüísticos modernos, como vamos a ver. De este conjunto, 173 etimologías corresponden a nombres comunes y 19 a nombres propios de lugar 5 . En cuanto a los apelativos, da una idea del alto nivel de calidad de las hipótesis de Urrea el hecho de que 140 de los étimos árabes -que denomina en una veintena de casos terminaciones, tecnicismo sin duda acuñado por él mismo, puesto que aparece en el Tesoro únicamente

1. Para los escasos datos biográficos conocidos acerca de este fascinante personaje puede verse Rodríguez / García-Arenal 2002. En cuanto a la relación entre Covarrubias y Urrea véase Bajo / Maíllo 2005: 31-32 y Ahumada 2007: XII.

2. S.v. aljamía se introduce la información de Urrea con las siguientes palabras: «Diego de Vrrea dize assí: "Para entender la sinificacion deste vocablo..."”; y s.v. açor se repite la opinión de Urrea en un mismo artículo dos veces con palabras prácticamente idénticas.

3. «Albufera. [...] Diego de Vrrea dize que vale [...]. En otra parte dize Diego de Vrrea que albufera se dize...». No hay constancia de ninguna obra impresa de Urrea, como subrayan Rodríguez / García-Arenal 2002: 499 y Bajo / Maíllo 2005: 31-32, n. 8. Tan solo parece segura su participación en la elaboración de un catálogo bilingüe árabe-castellano de los fondos árabes antiguos de El Escorial, según Rodríguez Mediano / García-Arenal 2002: 509.

4. Probablemente el número real de datos procedentes de Urrea es algo mayor. La hipótesis etimológica expuesta s.v. alcáçar, por ejemplo, sin duda se basa en notas proporcionadas por Urrea, a juzgar por el uso de la expresión terminación en referencia al étimo y la indicación explícita de este como caiserun: «Pero lo más cierto es ser Arábigo, de al-artículo y caizar, que en terminación Arábiga es caiserun, domus Caesarea.» Similar es el caso de albarda.

5. Naturalmente no podemos saber en qué criterios se basa la selección de las voces explicadas por Urrea: ¿̨ue el propio Covarrubias quien consultó al arabista acerca de un conjunto de voces concretas, o fue este último el que se limitó a proporcionar la interpretación de una serie de casos que veía claros? 
asociado a las etimologías atribuidas a su persona- identificados puedan considerarse acertados desde el punto de vista de la lingüística moderna, si tomamos como referencia los diccionarios etimológicos modernos (Corominas / Pascual 1980-1991 y Corriente 1999). Esta tasa de acierto, que asciende a un $81 \%$, resulta en efecto sorprendentemente elevada, tanto en comparación con la que alcanzaban otros estudiosos contemporáneos como si tenemos en cuenta que en la época aún apenas nada se sabía de leyes fonéticas ni se recurría a documentación léxica histórica, y las ideas sobre la historia de las lenguas eran poco más que creencias y mitos dominados por la religión y las ideologías. Los casos en que Urrea no atinó, además, son por lo general perfectamente comprensibles. La mayoría de las veces se trata de voces cuya etimología exacta plantea todavía dudas importantes a los etimólogos de nuestro tiempo o requiere explicaciones que solo la lingüística moderna ha podido dar: voces de origen oscuro como aguinaldo, formas que se habían alejado notablemente del étimo árabe en el proceso de adaptación fónica al castellano (alfalfa $<$ fásfașa < ár. cl. fișfisah; alifafe < náfah), germanismos como alvergue o gaita (voz esta última que, además, se había extendido al árabe y al turco, lo que hace fácilmente comprensible la opción de la etimología árabe), voces hispánicas prerromanas transmitidas por el mozárabe y el árabe (alpargate), etc.

Pero Urrea no se limita solo a identificar los étimos árabes de los que parten las voces castellanas, sino que en la mayoría de los casos (en 143 ocasiones, concretamente) indaga además sobre el origen de la voz árabe: es decir, reconstruye la historia de dicha forma dentro del propio árabe, determinando bien la raíz de la que deriva, bien el idioma desde el que se incorporó un préstamo al árabe, por lo que Urrea va mucho más allá de estudiar el origen árabe de los arabismos incorporados al español, para investigar problemas etimológicos del propio árabe. También en este terreno los aciertos son numerosos, según revela el cotejo de las propuestas de Urrea con los resultados de la investigación etimológica moderna, pues reconstruye correctamente el origen dentro del árabe de las voces que pasarían al castellano como aduar, albacea, alvalá, albañir, alvayalde, alcabala, alcacel, alcalde, alcohol, Alcorán, alcuzcuzú, alférez, alfilel, alhaja, almártega, arroba, axaqueca, algarbe, álgebra, alguaquida, alharaca, alicates, almirez, almofrex, almoxarife, almoneda, alquitara, alquitrán, anacala, añafil, arraxaque, arroba, atalaya, jábega, jeque, magacén, mameluco, maquila y mezquita. Naturalmente, dada la dificultad de la materia, forzosamente también hay casos en que la investigación moderna prefiere una interpretación distinta de la propuesta por Urrea, si bien hay que destacar que la mayoría de las veces se trata de etimologías que entrañan algún tipo de dificultad o incluso son controvertidas en mayor o menor medida hasta hoy (alferecía). En no pocos casos, la dificultad deriva del hecho de que la voz árabe a su vez es préstamo de otra lengua, como ocurre con alambique, albornía, alcaduz, alcarchofa, alcarraza, alcayata o alcuza. Urrea, que dominaba 
también idiomas como el turco o el persa, era en muchos casos plenamente consciente de este hecho, e incluso lanzaba algunas hipótesis, unas veces con acierto $^{6}$, otras con menos fortuna ${ }^{7}$.

Con cierta regularidad, Urrea se detiene a justificar sus interpretaciones mediante argumentos lingüísticos de diverso tipo. En treinta y tres casos explica su etimología desde el punto de vista morfológico ${ }^{8}$; un ejemplo representativo es almotazén: «Diego de Vrrea dize ser su terminación Arábiga, muhtesibun, participio agente, del verbo ahtesebe, que sinifica tomar cuenta con eficacia y rigor de justicia: al es artículo, mo, signum instrumentale, atacen o tacen, corrompido de tesibun o tecibun...». Menos frecuentes -he contado once casos- son las explicaciones fonéticas ${ }^{9}$, como la que ofrece para azeña: «[...] viene esto bien con lo que dize Diego de Vrrea, que en su terminación Arábiga se dize senieytum, del verbo sane, que sinifica facilitar. La $s$ se buelue de ordinario en $z$, y assí de zenietum, con el artículo dezimos a-zenietum, y de allí azeña.»

En diecinueve ocasiones ${ }^{10}$ Urrea justifica el aspecto semántico de la etimología que propone, como sucede por ejemplo en adehala: «Es nombre arábigo, según Diego de Urrea, del verbo dehale, que vale sacar alguna cosa o entrar, porque se saca de más y entra con lo que se compra; y este término es usado en África.» Este último caso nos muestra cómo el arabista ocasionalmente completa su interpretación incluso con algún dato lingüístico de carácter dialectológico. Aún más interesantes son sus observaciones sobre fenómenos sociolingüísticos como las que ofrece acerca de alguaquida y atalaya ${ }^{11}$ :

ALGVAQVIDA [...] Vrrea le da su terminación Arábiga vequidetun, del verbo vecade, que sinifica encender, aunque en lengua grossera y poco cortesana; de manera que nosotros auíamos de boluer al vquida; y esto se guardò en al-vquete, que sinifica lo mesmo que alguaquida. Mas como tenemos dicho en la palabra alguazil, los Moriscos de España pronuncian la $v$ por $g u$.

ATALAYA [...] Diego de Vrrea la llama Talayetun, del verbo ettalaa, que sinifica subir en alto alargando el cuerpo para descubrir más campo, pero que cortesanamente se llama el atalaya sartun.

6. Por ejemplo, cuando explica genizaro como «nombre turquesco y que vale 'nuevo ejército'».

7. Como cuando deriva axedrez del persa sadreng 'comezón de sarna'.

8. Alcahuete, alcalde, alfayate, almártega, atanquía, álgebra, almádena, almagre, almaizar, almalafa, almarraja, almenara, Almería, almivar, almirez, almizcle, Almodóvar, almofrex, almohada, almohaza, almoxarife, almoneda, almotazén, Almuñécar, alpargate, alquitrán, daifa, magacén, mamelucos, maquila, mezquino, mezquita y zaquizamí.

9. Alcacel, almártega, azeña, adufe, alguacil, alguaquida, almirez, almotazén, arrope, çalea y çaquiçami.

10. Aduar, alambique, alvergue, albóndiga, alcaduz, alcoba, alcohol, Alcorán, alcorça, alcotán, alcuza, alcuzcuzú, aldava, alfeñique, alférez, alfilel, alhaja, almártaga y berenjena.

11. Véase otro caso s.v. alguazil. 


\section{Los «escritos» de Diego de Guadix}

Con motivo de la primera edición de la Recopilación de algunos nombres arábigos, E. Bajo y F. Maíllo (Guadix 2005: 31-41) realizaron un minucioso cotejo entre la información contenida en ese texto redactado hacia 1593 y conservado en forma de un único manuscrito custodiado en la Biblioteca Colombina por una parte, y la que en el Tesoro se atribuye a Diego de Guadix por otra. Las coincidencias que observaron son indiscutibles y evidentes: la mayoría de las etimologías atribuidas a Guadix se corresponden con las propuestas en la Recopilación, si bien generalmente se cita el texto solo «muy parcialmente» (Bajo / Maíllo 2005: 35), más que nada para explicar el aspecto semántico de la etimología. No obstante, Bajo / Maíllo llaman la atención sobre toda una serie de discrepancias notables que requieren una explicación. Además de las meramente gráficas, carentes de importancia tratándose del Tesoro, señalan cómo en numerosos casos Covarrubias emplea palabras que parecen suponer un cambio del texto de Guadix (pandero por panderete, lugar de praderías por prados, mezcló por revolbió, etc.); en ciertos casos, incluso, atribuye a Guadix información que no figura en el manuscrito de la Colombina, como las etimologías de ciertas voces (alcarchofa, alcuza); en algunas entradas (alcuzcuzú, arfil, atapar) la información procedente de Guadix no presenta parecido alguno con la contenida en la Recopilación, hasta tal punto que "parece [...] extraída de dos obras totalmente diferentes»; Bajo / Maíllo incluso identifican una entrada, Alderete, en la que se remite a Guadix a pesar de que la Recopilación no registra artículo alguno dedicado a tal voz (2005: 37-38). Llaman la atención (Bajo / Maíllo 2005: 32), además, sobre el hecho de que Covarrubias no mencione nunca el título de la Recopilación, sino que hable solo de unos "escritos» ${ }^{12}$, expresión que hace dudar de que se tratara de un texto que diera la impresión de una obra unitaria, completa y terminada, como sí ocurre con el ms. de la Colombina, que contaba incluso con licencia de impresión. En vista de estos y otros indicios, llegan a la conclusión de que «lo más sensato es, por una parte, poner en duda que Covarrubias haya manejado el mismo manuscrito depositado en la Biblioteca Colombina, y, por otra, creer que Covarrubias disponía de escritos de Guadix, cuyo texto, en gran medida, coincide con el de la Recopilación» (Bajo / Maíllo 2005: 39).

Ahora bien, las llamativas divergencias -que tanto destacan Bajo / Maíllo debido al aspecto específico que estudian- entre el texto de la Recopilación y las palabras con que se exponen en el Tesoro las hipótesis de Guadix no tienen que corresponder -salvo en casos muy concretos- a discrepancias sustanciales, sino que pueden tener su explicación más que nada en la peculiar forma de trabajar de Covarrubias. Parece significativo el que el canónigo haga referencia

12. Varios autores han hecho conjeturas sobre cómo pudo llegar a manos de Covarrubias el texto inédito del franciscano granadino: Bajo / Maíllo (2005: 32), Ahumada (2007: XII) apuntan a una conexión a través del hermano de Covarrubias, obispo de Guadix, y Alvar (2011: 38) a un posible encuentro en Roma en 1597. 
a su modo de acceder a la obra con la forma verbal he visto («he visto unos escritos del Padre Guadix»). No parece afirmar con ella que tuviera presente el texto de Guadix constantemente mientras redactaba su diccionario; más bien parece aludir a que tuvo acceso a los manuscritos en algún momento anterior, que pudo aprovechar para elaborar una serie de notas, unos apuntes en los que naturalmente no recogía el extensísimo texto -tengamos en cuenta que incluye más de 4000 artículos de muy variada extensión- de modo completo y literal, sino tan solo una selección de artículos cuyas ideas principales se reproducían de modo muy resumido. Si comparamos por ejemplo los artículos dedicados en ambos textos a la voz aljofaina:

\begin{tabular}{|c|c|}
\hline Recopilación (Guadix 2005: 353) & Tesoro (Covarrubias 1611: 106) \\
\hline $\begin{array}{l}\text { Axofayna. Llaman en algunas partes d'España, } \\
\text {.i., en el reyno de Toledo, a vn vasso o conquilla } \\
\text { de barro, a que en otras partes d'España llaman } \\
\text { almofía o barreña. Viene d'este nombre jufe, que } \\
\text { en arábigo significa beço, .i., labium; de suerte } \\
\text { que todo junto, alxufe [sic], significará el beço } \\
\text { o el labio; y el -na es afixo de primera persona } \\
\text { del plural y significa nuestro; de suerte que todo } \\
\text { junto, alxufena o alxufna, significa el nuestro } \\
\text { beço, .i., el nuestro labio, .i., la nuestra beuida } \\
\text { o la nuestra sorbida, lo qual se haze llegando el } \\
\text { dicho vaso a los labios... }\end{array}$ & $\begin{array}{l}\text { Axufayna. [...] El padre Guadix dize } \\
\text { estar corrompido de xufe, que sinifica } \\
\text { labio, porque la axufayna tiene vn borde } \\
\text { gruesso y redondo, como repulgo, y por } \\
\text { otro nombre se llama almofía. }\end{array}$ \\
\hline
\end{tabular}

no podemos sino llegar a la conclusión de que Covarrubias copió del texto de Guadix únicamente la información que le pareció esencial, e incluso esta la reprodujo de un modo extremadamente conciso y libre: apuntaría de forma aproximada el étimo (xufe, en lugar del original jufe, sin tener en cuenta el elemento -na) y su significado "labio» (aunque Guadix realmente hablaba de beço), así como un sinónimo regional almofía. En cambio, omitiría por completo la (poco convincente) justificación semántica del étimo ofrecida por Guadix, al igual que una segunda hipótesis (al + jafayna «el curado avemos»o «el medicado avemos») aún menos creíble que ocupaba más de la mitad del extenso artículo. En el momento de redactar el artículo correspondiente del Tesoro, Covarrubias, no obstante, sintió la necesidad de explicar semánticamente el étimo adoptado de Guadix, pero al no recordar ni tener anotada la explicación original tuvo que recurrir a una argumentación propia, que resultaría ser divergente de la original de Guadix.

No es este, ni mucho menos, un caso aislado. También la comparación de otros muchos artículos nos confirma que Covarrubias se anotó, mientras disponía de los textos manuscritos de Guadix, poco más que los étimos árabes y su significado; este hecho, unido a la conocida forma espontánea y apresurada de trabajar de Covarrubias, nos explica por qué no se cita ni una sola vez de forma literal a Guadix (cosa que sí ocurre, al menos ocasionalmente, con otras fuentes, incluso con Urrea), y por qué las interpretaciones atribuidas a Guadix, 
a pesar de coincidir en el fondo con la Recopilación, presentan tantas diferencias sobre todo formales. Las notas debieron de ser tan escuetas que no solo le obligaron a reformular con sus propias palabras las ideas de Guadix, sino que a veces no supo siquiera cómo interpretarlas, a juzgar por el comentario «si no me engaño» que a veces inserta ${ }^{13}$.

Como ya destacó M. Alvar Ezquerra (2011: 38), Diego de Guadix es la fuente arabística más citada en el Tesoro: de ella proceden un total de 209 etimologías de apelativos y 56 de nombres propios, casi todos topónimos. Este constante recurso a los «escritos» de Guadix, sin embargo, no se debe necesariamente a que Covarrubias sintiera una especial predilección por esta fuente, sino más bien a que constituía un repertorio ingente de información muy cómodo de explotar, puesto que solo se trataba de extraer la información más interesante, presentada en un orden alfabético paralelo al del diccionario que Covarrubias estaba redactando, y trasladarla al Tesoro. Aun así, el canónigo no aprovechó más que un 9,19\% de los 2275 artículos referentes a nombres comunes del texto de Guadix, y tan solo un 2,72 \% de las 2061 relativas a nombres propios.

Es evidente, pues, que realizó - probablemente no en el momento de redactar el Tesoro, sino ya durante la elaboración de sus notas a partir de los manuscritosuna criba bastante drástica del material que le ofrecía Guadix, extrayendo tan solo lo que le interesaba y le resultaba convincente. La comparación de los datos incluidos en el Tesoro con la Recopilación permite reconstruir hasta cierto punto los criterios de selección aplicados por Covarrubias. Así, rechazó bastante sistemáticamente las etimologías del tipo más representativo del planteamiento de Guadix: las basadas en acumulaciones de morfemas de todo tipo, como por ejemplo cambalache < quembalàach = quem 'quántos' + bal 'con la' + àach 'sed'. Esta postura crítica de Covarrubias, aunque no la mantuviera en todos los casos, es muy sensata ${ }^{14}$, y cuando en algunos casos reproduce tales etimologías ${ }^{15}$ probablemente no lo hace sino de una manera un tanto mecánica e irreflexiva. Aún más crítico se muestra Covarrubias ante las numerosas etimologías híbridas propuestas por Guadix; como ya destacaron Bajo / Maíllo (2005: 40-41), las rechaza prácticamente todas (salvo las que contienen el artículo árabe agregado a un elemento léxico procedente de otra lengua), y en una entrada incluso las descalifica explícitamente: «El nombre de Almagro, el padre Guadix y otros con él, quieren se aya dicho de al-ma-agua y de agro; es assí que las aguas de aquella villa y contorno tienen vn sabor agrio y austero aunque dizen ser muy sanas; pero no me persuado a que los Moros compusiessen el nombre de dos dicciones diferentes en lenguaje.»

13. «Ripio. [...] El padre Guadix, si no me engaño, dize ser Arábigo, de ripel, que vale piedras menudas con arena». Cf. los comentarios de Bajo / Maíllo (2005: 40) acerca de esta fórmula.

14. F. Corriente ha expuesto detalladamente lo desacertado de este y otros planteamientos de Guadix. Su juicio, que naturalmente se basa en una valoración desde la perspectiva de la lingüística moderna, es que la obra causa una «impresión de disparate predominante» (Corriente 2005: 94).

15. Bastardo, calabozo, zahori, Baeza, Daimiel y Valsain. 
Otros muchos étimos propuestos por Guadix pudieron parecerle poco verosímiles, como sucede a cualquier lector con un mínimo de sentido crítico. De hecho, en más de una ocasión se distancia de la hipótesis de Guadix mediante matizaciones que expresan escepticismo ${ }^{16}$, como ya pusieron de relieve Bajo / Maíllo (2005: 40), y el rechazo llega a ser rotundo en el caso de halcón: «El padre Guadix dize que este nombre Halcón es Arábigo, y que vale alcançador; sin duda se deuió engañar, pues la etimología Latina es más antigua y recebida de todos».

A pesar de la criba llevada a cabo por Covarrubias a la hora de extraer información de los escritos de Guadix, y a pesar de su actitud reservada ante esta fuente, más de dos tercios de las etimologías adoptadas de Guadix son erróneas (132, frente a 63 correctas; recordemos que en el caso de Urrea el porcentaje de aciertos es superior al $80 \%$ ). En esos casos, Covarrubias quizá incluyó el dato de Guadix a pesar de sus dudas porque no disponía de una alternativa, o simplemente porque manejaba sus fuentes de una forma un tanto rutinaria (de hecho, expone no pocas etimologías que él mismo cuestiona abiertamente o incluso rechaza de forma explícita dentro del mismo artículo).

\section{El Compendio de Francisco López Tamarid}

La tercera fuente arabística explotada con regularidad por Covarrubias -la cita en 114 ocasiones- es el Compendio de López Tamarid, la más antigua obra lexicográfica dedicada a los arabismos del español. Dado el escasísimo desarrollo de la microestructura de esta obra, que más bien constituye un esbozo que un verdadero diccionario de arabismos (Ruhstaller 2013: 268), Covarrubias naturalmente no pudo extraer sino una cantidad muy limitada de información, que aprovechó principalmente para confirmar la adscripción al estrato árabe que él mismo intuía para muchas voces ${ }^{17}$, así como para documentar los significados, o al menos ciertas acepciones específicas ${ }^{18}$, de cerca de cuarenta arabismos poco conocidos entre los hablantes de su época. Se trata casi siempre de arcaísmos (foluz, helga, almogávares), de dialectalismos ${ }^{19}$ (nagüela, algares, algayda, algaba, alhamel, almandrabe, almocrebe, azulaque,

16. Al hablar de baylío, por ejemplo, comenta «El padre Guadix quiere que sea Arábigo, y que vale tanto como el señor de la casa. No sé si tiene razón», y tras exponer la etimología de cuchar adoptada de Guadix advierte: «no sé si tiene fundamento».

17. En 41 casos (adivas, asarabacar, aspa, etc.) se limita a afirmar que Tamarid cuenta el vocablo en cuestión entre los arábigos.

18. "Atayfor, plato hondo donde se suelen seruir a la mesa las viandas guisadas con algunos caldillos. [...] Tamarid, mesa redonda.»; «alcatifa, tapete o cubierta de lana o seda que se pone para cubrir alguna mesa o banco.[...] Francisco López Tamarid: alcatifa es alhombra, o suelo que se echa en el edificio.» Algunas de las definiciones contenidas en el Compendio que llamaron la atención de Covarrubias, sin embargo, con toda seguridad no corresponden al arabismo español, sino a su presunto étimo árabe (rehén 'prenda', baharí 'halcón que passa la mar').

19. Nos consta la existencia de restricciones diatópicas por ejemplo gracias a las marcas de uso de que proveyó Diego de Guadix buena parte de las voces recogidas en su Recopilación. 
añacea, regayfa, mazarí, monfi) o de voces cuyo uso apenas había trascendido el habla de los moriscos («xabeba, cierta forma de flauta morisca, Tamarid»; atayfor). Ocasionalmente Tamarid le aporta, además, alguna variante formal menos conocida en el uso de la época, como alquicer de alquicel («alquicel [...] Tamarid le llama alquicenı), o alhábega de albahaca.

La segunda parte del opúsculo de Tamarid está dedicada a topónimos de presunto origen árabe. Del total de 75 nombres estudiados, Covarrubias extrae información acerca de veinte: Axarquía [de Málaga], Álava, Albaicin, Alcaçaba, Alhambra, Alixares, Aranjvez, Badajoz, Calatañoz, Darazután, Escurial, Genil, Gibraltar, Guadalaviar, Guadiana, Guadix, Hiznatorafe, Loxa, Zacatin, Zocodover.

\section{Otras fuentes}

Bastante menos información extrajo Covarrubias de una cuarta fuente: Juan López de Velasco. La obra consultada puede identificarse con la Orthographia (1582), en la que figuran numerosas etimologías debido a que el autor justificaba sus propuestas ortográficas con argumentos etimológicos. Covarrubias aprovechó los datos - muy parcos, aunque en la mitad de los casos lingüísticamente correctos- que le brindaba esta fuente para declarar el étimo de veintiséis presuntos arabismos -acelga, acemite, aceña, albacea, albahaca, albóndiga, alcacel, alcaravea, alhóndiga, alhorza, aljaba, Almazán, Argel, arrazife, atalvina, atarazana, azafate, azafrán, bodoque, cendal, hogaza, horro, jazmin, taça, çafra y çanahoria-, y ocasionalmente encontró en la obra también algún dato semántico (taluina). López de Velasco a su vez había extraído sus etimologías arábigas sin lugar a dudas del Vocabulista de Pedro de Alcalá, según revela la comparación de las dos obras:

\begin{tabular}{|l|l|}
\hline Vocabulista & López de Velasco \\
\hline Çanahoria yerua e rayz. Yçfernia & çanahoria, de izfornia \\
\hline Albahaca. Habăca. Habăq & albahaca, de habaca, traspuestas las sylabas \\
\hline Alhöndiga. Fondăq & alhóndiga, de fondaq, que es bodega \\
\hline Açelga. Cëlque. celq & acelga, de celque \\
\hline Aceña. Cinnia. çavı̆ni & aceña, cinia \\
\hline
\end{tabular}

Las restantes fuentes no fueron consultadas por Covarrubias sino muy esporádicamente. Extrajo dos etimologías (marrado y çaguán) de lo que denomina Vocabulario del Arzobispo de Granada ${ }^{20}$; cuatro del Brocense

20. ¿Se tratará del Vocabulista de Pedro de Alcalá? No encuentro las voces en cuestión en esa obra escrita durante el mandato de Hernando de Talavera como arzobispo de Granada; del poco esmero de Covarrubias en relación con esta fuente nos habla también el hecho de que llame al 
(amapola, azulejos, naipes, zerbatana); tres del Padre Mariana (se trata de topónimos: Algarbe, Almaguer y Granada); una de Pedro de Palencia (cebolla), e igualmente una de León de África (almirante). Es muy probable que estos autores a su vez se basaran en otras fuentes anteriores que, no obstante, son difíciles o imposibles de localizar o incluso pueden ser puramente orales.

Finalmente cabe señalar que el Tesoro contiene numerosos comentarios sobre presuntos arabismos (217 casos) que no se atribuyen a ningún autor concreto. Generalmente se trata de afirmaciones muy escuetas y superficiales ${ }^{21}$, que bien pueden reflejar simples conjeturas del propio Covarrubias o de personas de su entorno con las que había debatido sobre cuestiones etimológicas. Otras informaciones cuyas fuentes no se identifican proceden de los autores que hemos estudiado en lo anterior, y a Covarrubias simplemente se le olvidó citarlos; así, el registro de los dialectalismos alpicoces y almetolí, por ejemplo, tiene su origen claramente en Tamarid, concretamente en los breves listados de arabismos murcianos y portugueses que incluye («almetoli. Es azeytera o alcuza»; «alpicoces. Son cohombros»), y también proceden del Compendio diversas etimologías toponímicas (Balnadú, Çocadover, Guadarranque, etc.).

\section{La aportación original de Covarrubias}

A pesar de su falta de conocimientos teóricos y prácticos de árabe ${ }^{22}$, Covarrubias no se limitó a acumular de forma mecánica el material que había encontrado en las fuentes que tenía a su alcance. En primer lugar, llevó a cabo una selección consciente de dicho material; recordemos, por ejemplo, que aprovechó solo una reducida parte del extenso diccionario de Guadix, probablemente porque tenía justificadas reservas respecto de su validez. En cambio, confiaba plenamente en Urrea, como manifiesta repetidamente de forma explícita, y como han destacado diversos autores ${ }^{23}$, con reconocimientos del tipo «Ambos dizen vna cosa, pero Vrrea en todo es más dotrinal» (almalafa). Estas manifestaciones no son meras expresiones de gratitud por la generosa ayuda prestada por Urrea, sino que reflejan que Covarrubias era muy consciente de la sólida base científica que subyacía a la opinión de Urrea. Aun así, la

arzobispo Bernardo de Talavera (s.v. marrado).

21. En 80 casos se trata de simples adscripciones al estrato árabe (del tipo «dizen ser arábigo»), e incluso este dato se formula como suposición basada sin duda en la apariencia fónica de la voz: «el nombre çanahoria es Arábigo, no alcanço su etymología»; «rafez [...] sospecho ser nombre Arábigo.»

22. Esta falta de conocimientos hizo que prestara mucha menos atención al aspecto formal de las etimologías que al semántico. De hecho, a menudo se limita a reproducir el significado etimológico y omite la mención explícita del étimo árabe, o reproduce este de forma inexacta (no es verosímil que Urrea, por ejemplo, le transcribiera los étimos de alcaduz, adarma o axuar como ladeze, dirhermum o xenterum, respectivamente), si bien es pensable que alguna que otra errata se deslizara también en el proceso de impresión del texto.

23. Dozy 1868: 3-4, Crespo 1992: 102, Bajo / Maíllo 2005: 34, Rodríguez / García-Arenal 2002: 505 . 
adhesión de Covarrubias no era incondicional, pues en absoluto se limitaba a reproducir la propuesta de Urrea cuando disponía de ella, y de hecho la decisión de recoger adicionalmente la opinión de otros autores hizo que se subsanara algún que otro desacierto de Urrea, como muestran artículos como los dedicados a alcándara, adufre o atanquía, donde es correcta la etimología propuesta por Guadix y errónea la de Urrea; en algún caso incluso se atreve a enmendar, con poca fortuna, personalmente al arabista ${ }^{24}$.

Son muchos los artículos en los que enumera las hipótesis de varios autores reflejando así el animado debate en que estaban inmersos los eruditos de la época. Cuando dichas hipótesis eran total o parcialmente coincidentes las reproducía para que se confirmaran o complementaran mutuamente ${ }^{25}$; cuando discrepaban las contraponía para que el lector eligiera la que más le convenciera (almadrava, ajorcas, almoxarife). No pocas veces aportaba además argumentos, reflexiones y valoraciones propias, ofreciendo así todo un estudio etimológico crítico de las voces (puede verse un ejemplo representativo s.v. Almodóvar).

Evidentemente, la argumentación de Covarrubias rara vez satisface las exigencias de la lingüística propiamente científica, aunque sí revela que intuía gran parte de los problemas identificados por los etimólogos modernos ${ }^{26}$. Un ejemplo especialmente interesante es su procedimiento en el caso de la etimología de albahaca, en cuyo estudio contrasta las opiniones de Urrea y López de Velasco aduciendo un interesante argumento lexicológico romance -la existencia de la forma catalana alfábega, que no presenta la metátesis- a favor de este último:

Es nombre Arábigo, aluahaca, vehecum del verbo veheca, que sinifica penetrar el celebro con suaue olor. Vrrea, de vehecum, dezimos beheca, y con el artículo al-veheca, y últimamente en toda corrupción aluahaca. El Catalán le mudó las consonantes, anteponiendo la $f$. en lugar de la $h$., como es ordinario, y posponiendo la $b$., y assí llama a la albahaca, alhábega o alfábega; y viene bien con lo que dize Iuan López de Velasco: albahaca, de habaca, traspuestas las sílabas.

Más frecuentes son las reflexiones sobre el aspecto semántico ${ }^{27}$ de las etimologías que reúne en sus artículos. En parte, las justificaciones del significado etimológico se encontraban ya en la fuente (sobre todo, en Guadix), en parte

24. "Alqvitara o alcatara [...] Diego de Vrrea dize ser sin duda Arábigo, y que en su terminación se llama quitaretum, distilatorio, del verbo catare, que sinifica distilar, pero yo entiendo que los Árabes tomaron este nombre de los Griegos, como otros muchos.»

25. Así sucede s.vv. almofrex, almonací, almohaza, algalia, álgebra, alguacil, almalafa, almanaque, Almodóvar.

26. Para las ideas toponomásticas que podemos rastrear en diversos autores de la época (Esteban de Poza, Diego de Guadix) puede verse Coseriu (2000: 60-61) y Ruhstaller (2012: 185-193).

27. Y, en el caso de los topónimos, el referencial; por ejemplo, intenta hacer plausible el étimo con significado «lugar de los renegados» postulado por Guadix para Almuñécar explicando que "por ventura los vezinos de aquel pueblo se auían buelto Christianos, y los Moros les pusieron este nombre.» 
las agregó el canónigo, dando así implícitamente por buenas las hipótesis ${ }^{28}$. Alguna que otra observación de Covarrubias parece contener un anticipo de los razonamientos que haría siglos después el método Wörter und Sachen. Así, por ejemplo, manifiesta sus dudas ante la etimología suministrada por Guadix para caço-«El Padre Guadix dize ser nombre Arábigo, y sinificar lo mesmo que tornillo o dornillo»- comentando "puede ser en quanto la forma, pero no en quanto a la materia, porque el vno es de madera y el otro de metal.»

Finalmente, Covarrubias con frecuencia no se limita a aprobar y comentar las etimologías arábigas que reproduce, sino que, además, las desarrolla retrotrayéndolas hasta su presunto origen último en hebreo. Esta práctica no supone ninguna crítica o enmienda a los autores que cita, ya que, desde la conocida posición filohebraísta defendida por Covarrubias, no había ninguna contradicción en admitir a la vez una etimología arábiga y otra hebrea más antigua, ya que todas las lenguas remontaban en último término a la lengua originaria prebabélica (cf. Reyre 2006: LI) ${ }^{29}$.

\section{COVARRUBIAS COMO TRANSMISOR}

Como hemos visto, el Tesoro incluye una recopilación crítica de la mayor parte del saber acumulado durante el Humanismo acerca de los arabismos del español. El diccionario proporcionaba un fácil acceso a una considerable cantidad de información, expuesta en un cómodo orden alfabético, y previamente seleccionada y valorada por un autor cuyo prestigio fue reconocido quizá no por sus contemporáneos, pero sí desde el siglo XVIII, momento a partir del cual ha sido objeto de una recepción cada vez más intensa. Los primeros impulsores de este reconocimiento fueron los fundadores de la Academia Española, que reivindicaron la obra explícitamente en el prólogo al Diccionario de autoridades, al que incorporaron una gran cantidad de datos del Tesoro (Seco 1988). En los artículos dedicados a arabismos, concretamente, integraron información sobre voces caídas en desuso que ya Covarrubias había obtenido gracias a la consulta de fuentes anteriores:

ALCOR. S.m. Lo mismo que Cerro, ò collado, según el P. Guadix citado por Covarr.

ALMIXAR [...] Lugar donde se ponen a secar los higos. Esta significación le da a esta voz el P. Guadix. Oy no tiene uso.

28. En el caso de adarve, por ejemplo, Covarrubias aclara el significado etimológico "golpeadero o heridero" propuesto por Guadix justificando "porque desde el adarue hieren con flechas y golpean con piedras a los que pretenden arrimarse a los muros», explicación no contenida en la fuente.

29. Un ejemplo representativo puede ser çaraças: «El padre Guadix dize ser nombre Arábigo que sinifica cadena, y que son vnos garauatillos eslauonados unos con otros los quales meten dentro de la carne con que ceuan al lobo, y assiéndosele a la garganta lo matan. Quádrame la Etimología, por quanto a mi parecer trae su origen del nombre Hebreo [...] çar, corona, seu circulus, quales son los eslauones de la cadena, por estar compuesta de anillos.» 
Como vemos en estos ejemplos, no siempre indicaban la mediación de Covarrubias en la recopilación de los datos. Este mismo hecho se comprueba también en las numerosas etimologías adoptadas del Tesoro, de las que hallamos cerca de cincuenta procedentes de Guadix tan solo en el tomo I del Diccionario de autoridades, y casi cien en el conjunto del diccionario; las citas de Urrea son algo menos numerosas. Algunas de estas etimologías se atribuyen directamente a su autor último, otras simultáneamente a este y a Covarrubias (no sin razón, ya que habían sido aceptadas explícitamente por este), y las de un tercer grupo se presentan como propias de este:

ATARRAGAR. [...] El P. Guadix dice que es voz Arabiga.

ALGUACIL. [...] Esta voz es formáda y compuesta del artículo $A l$ y de la palabra Arábiga Guacir, que vale Ministro de justicia, en que conforman los Padres Alcalá, y Guadix, Urréa, y otros, citados por Covarr.

ALMARJO. [...] Covarr. y el P. Guadix dicen es palabra Arabiga de Almarch, que significa Prado, ò Vega.

Los académicos generalmente se limitaban a reproducir las hipótesis etimológicas expuestas en el Tesoro, aunque en algunas ocasiones ofrecían una valoración:

ATANQUIA. [...] El P. Alcalá dice ser su origen de la palabra Arábiga Tanquia, que afirma el P. Guadix que corresponde à cosa que limpia, y esta paréce la mejor etimología entre muchas que se dán para esta voz.

Estos datos se transmitieron -con alguna que otra modificación debida a una nueva consulta del Tesoro- a las ediciones posteriores del diccionario académico, al menos hasta la supresión general de la información etimológica a partir de la edición de 1803. Dado que en la época de la redacción del primer diccionario académico la ciencia etimológica no había hecho avances notables respecto de Covarrubias, las etimologías de este se reproducían y aceptaban prácticamente sin reservas (aunque es cierto que los académicos hicieron el esfuerzo de consultar alguna fuente complementaria, especialmente el Vocabulista aránigo de Pedro de Alcalá). Este hecho que dio lugar a que muchas hipótesis carentes de base científica, repetidas una y otras vez desde Covarrubias, alcanzaran una difusión enorme, al menos hasta la revisión que se llevó a cabo con motivo de la reintroducción de las etimologías a partir de la edición de 1884 con el asesoramiento de arabistas como Eguílaz y Yanguas.

A pesar del enorme progreso que experimentó el estudio de los arabismos en la segunda mitad del s. XIX, se percibe con claridad también en las obras de los arabistas de esa época la gran fuerza de propagación que ha ejercido el Tesoro. En el prólogo a su Glossaire, Dozy comenta las aportaciones al estudio de los arabismos de Tamarid, Guadix y Urrea, reconociendo explícitamente que le constan únicamente a través del Tesoro (Dozy 1868: 3). Aunque atribuye a los dos primeros un perfecto dominio del árabe vulgar, se muestra muy escéptico 
ante sus etimologías ${ }^{30}$, que califica de modo general de "conjectures hasardées"; en cambio, confirma el juicio de Covarrubias acerca de la valía científica de Urrea afirmando que "cet éminent connaisseur de la langue arabe mérite à juste titre la confiance que lui a accordée le lexicographe espagnol. Il donne quelquefois des renseignements précieux sur des mots árabes quion chercherait en vain dans les dictionnaires». Su anuncio de citar y comentar a Urrea con frecuencia en el Glossaire, sin embargo, no se cumple realmente, pues lo menciona tan solo en ocho ocasiones $^{31}$. A pesar de ello, es muy probable que Dozy se inspirara en las propuestas de Urrea en muchos más casos.

Esta tendencia de Dozy a no citar sus fuentes es precisamente un defecto que le achacó Leopoldo Eguílaz y Yanguas (1886: XIV). También este arabista explotó el Tesoro asiduamente, si bien llama la atención el hecho de que aprovechara solo muy parcialmente los datos arabísticos más valiosos que le ofrecía la fuente, los procedentes de Urrea, pues en su Glosario nombra a este autor explícitamente tan solo en 43 artículos (es decir, pasa por alto 130 propuestas etimológicas referentes a apelativos, muchas de ellas acertadas), y, lo que es más grave, hace caso omiso de la inmensa mayoría de las valiosas $\mathrm{y}$ originales informaciones y reflexiones, tan justamente apreciadas por Covarrubias y Dozy ${ }^{32}$. Es evidente que Eguílaz no concedía a Urrea un valor especial. Más importancia parecía darle a Guadix ${ }^{33}$, autor al que citaba mucho más frecuentemente, e incluso indicaba a menudo como suministrador de una etimología que también, y con mejor justificación, había ofrecido Urrea, sin que se reconozca este hecho (alcohol, alcorza, alcuza, alcrebite, alhaja, almohaza, arroba, alfayate, etc. $)^{34}$. Tampoco hace referencia Eguílaz a que Urrea no constituye una fuente independiente del Tesoro ${ }^{35}$.

Todavía en los estudios del siglo XX dedicados a los arabismos del español se hace sentir con fuerza el influjo de Covarrubias. Incluso una obra tan crítica y tan rigurosamente documentada como el $D C E C H$ aprovecha no pocas veces

30. Dozy acude a Guadix a través del Tesoro once veces, unas para ratificar sus etimologías en mayor o menor medida (arriates, baladi, hovero, moxi), otras para cuestionarlas o rechazarlas (alferecía, alboroto, alforza, arriero), o simplemente para citarlas (atocha, rabadán). A Tamarid remontan algunos datos semánticos transmitidos hasta Dozy a través de Covarrubias (alhamel, almea, añacea, arriates, azulaque, baharí, oro de Tíbar).

31. En tres casos, Dozy da por válida o al menos considera interesante la etimología de Urrea (adahala, almártaga y alborga), mientras que en otros cinco la cuestiona o incluso la rechaza abiertamente (alcandora, alforza, almadraba, arriero, azagaya).

32. Los casos en que las cita o comenta son contados: ajarafe, ajedrez, aduar, adahala, acicate ( Urrea (ap. Cov., Tesoro) lo deriva de sicatum y con el artículo asicatum»).

33. La recepción de Guadix por parte de Eguílaz ha sido estudiada a fondo por Bajo / Maíllo (2005: 50-52). Como destacan estos autores, Eguílaz no se limitó a acceder a los datos de Guadix a través del Tesoro, sino que manejó, además, directamente el manuscrito conservado en la Biblioteca Colombina.

34. O trata al mismo nivel a López de Velasco y a Urrea (s.v. albacea, por ejemplo, se remite escuetamente a «López de Velasco y Urrea»), a pesar de que la información que ofrece el segundo, además de original, es mucho más completa que la del primero.

35. Es extraño el caso de la voz algebna: Eguílaz (1886: 179) invoca a Urrea como fuente, pero tal registro no se encuentra en el Tesoro. 
la información referente a los arabismos contenida en el Tesoro, y no solo como fuente de documentación léxica, sino incluso para extraer etimologías. Algunas se admiten plena o parcialmente (por ejemplo, las relativas a luquete, zahareño y zarzahán), otras se rechazan de plano o se rebaten con argumentos (zaida), o se citan simplemente a título de curiosidad (haragán). Una vez más se comprueba la importancia de Covarrubias como transmisor de información procedente de otros autores: Corominas accede a través de él a datos lingüísticos varios ${ }^{36}$, sobre todo, como ya señalaron Bajo / Maíllo (2005: 67-69), a las etimologías de Guadix (zaquizami ${ }^{37}$, tabique, toca ${ }^{38}$, zarza) o López de Velasco (atalvina, s.v. talvina, aunque califica la propuesta de "etimología fantástica»). Dado que la fuente inmediata de esta información es el Tesoro, y dado que Covarrubias funde en su redacción todos los datos que acumula y comenta, a menudo se atribuye a este lexicógrafo información que realmente procede de fuentes anteriores; así, se identifica a Covarrubias como autor de las etimologías de cendal (< ár. vg. sendâl "chapa») y de daifa (< dáyfa «dueña, señora») a pesar de que corresponden en último término a López de Velasco y a Urrea, respectivamente.

Ahora bien, Corominas, plenamente consciente de los procesos de transmisión a través de los cuales ha llegado hasta nosotros la información lexicográfica y de los riesgos que entrañan, se muestra muchas veces escéptico ante los datos que maneja y nos descubre no pocas informaciones erróneas. De hecho, advierte en reiteradas ocasiones de datos viciados derivados de una consulta descuidada de la fuente ${ }^{39} \mathrm{y}$, sobre todo, de informaciones e hipótesis sin fundamento científico que, a fuerza de ser repetidas una y otra vez por los autores sucesivos, acaban por ser consideradas como verdaderas e incuestionables. Un ejemplo representativo es la voz arriate. Covarrubias extrae de Tamarid una acepción 'calzada, camino o paso', inexistente en español y originada por una hipótesis etimológica errónea. Los autores del primer diccionario académico en este caso, seguramente por prudencia (y con buen criterio), no adoptaron el dato, aunque sí lo hicieron sus sucesores en una nueva revisión llevada a cabo con motivo de reedición del Diccionario de autoridades en 1770: localizaron en el Tesoro el dato omitido en la primera edición y lo incorporaron como acepción adicional a la segunda, indicando: «Según el Padre Guadix, y Tamarid, citados por Covarrubias, significa calzada,

36. Como primeras documentaciones -algaida, hadrolla (s.v. trola)-, pormenores semánticos - mogollón, tarbea - o datos sobre el hispanoárabe que conocían de primera mano autores como Guadix (atocha).

37. Comenta: «Ya explicaba bien la etimología el Padre Guadix, citado por Covarr.»

38. En este caso, Corominas, consciente del riesgo de citar fuentes de segunda mano, matiza la información que Covarrubias atribuye a Guadix: «De hecho el P. Guadix (1593), que conocía el árabe español de viva voz, al afirmar que toca viene del árabe, dijo (si prestamos fe a Covarr.) que en árabe se decía toque...».

39. Por ejemplo, advierte: «no conozco testimonios; tampoco los tengo del raro zato, citado por Autoridades como si estuviera en el P. Guadix (pero Covarr. sólo dice que éste habla de zatico)». 
camino ó paso». Desde ese momento el registro se ha repetido mecánicamente (y, naturalmente, desprovisto del comentario de que se trataba de un dato extraído por Covarrubias de una fuente anterior) hasta la última edición del diccionario académico, y ello a pesar de que Corominas advirtió hace décadas de su falta de fundamento y de la necesidad de suprimirlo del diccionario académico (cf. Ruhstaller 2013: 263).

\section{Conclusiones}

Como ha revelado el estudio precedente, Covarrubias desempeñó un importante papel como recopilador crítico del saber acumulado durante el Humanismo español acerca del elemento árabe presente en la lengua española, una información que había extraído de muy diversas fuentes ${ }^{40}$. Entre ellas sobresalen claramente Guadix y Urrea, y ello por dos razones. En primer lugar, por la gran cantidad de información que le aportaron, puesto que del total de 628 etimologías arábigas expuestas en el Tesoro, 265 proceden de Guadix y 192 de Urrea; estas 457 etimologías constituyen más del $70 \%$ del total de las recogidas en el diccionario. Estas fuentes, en segundo lugar, se caracterizan por su difusión extremadamente limitada: el texto de Guadix, inédito hasta nuestro siglo, había llegado a manos de Covarrubias de modo casual en forma manuscrita; y la información de Urrea, por su parte, ni siquiera constituía una obra propiamente dicha, sino tan solo un conjunto de hipótesis que el autor había cedido a Covarrubias a petición personal de este.

El gran mérito de Covarrubias consiste, pues, en haber puesto a disposición del lector una amplia visión de conjunto del saber arabístico de su época a través de una obra de consulta ordenada alfabéticamente, y en haber hecho pública una información prácticamente inaccesible tanto en su época como en las posteriores hasta el siglo presente (cf. Ahumada 2007: XI). Incluso podemos decir que Covarrubias dio un impulso decisivo a la investigación en este terreno, ya que fue él quien, a través de sus consultas directas, movió a Diego de Urrea, probablemente el mejor arabista de su tiempo por mucho que no se conserve ninguna obra suya, a dejar constancia escrita de sus conocimientos y sus ideas. Urrea respondió con tal generosidad a la petición de Covarrubias que el conjunto de los datos transmitidos a través del Tesoro, si se contemplara aisladamente, bien podría considerarse un estudio etimológico autónomo, tanto por la cantidad de voces que interpreta como por la calidad científica -no igualada hasta la segunda mitad del siglo XIX- de su análisis. Dada la intensa recepción de que ha sido objeto el Tesoro durante siglos, y

40. Esta valoración naturalmente no solo es válida en lo que respecta al léxico de origen árabe, pues en general puede afirmarse que el Tesoro constituye en gran medida una recopilación comentada, una síntesis crítica del saber del momento (realizada con un sentido crítico a veces un tanto peculiar, es cierto, aunque siempre muy representativo de la forma de pensar de su tiempo; cf. Ruhstaller en prensa). 
dada también la falta de aportaciones nuevas al tema debida al declive que sufrieron los estudios arabísticos en el siglo XVII (Monroe 1970: 23), la información recogida por Covarrubias acerca del léxico español de origen arábigo se transmitió a numerosas obras lexicográficas posteriores, unas veces para ser analizada críticamente, otras para ser repetida de forma mecánica ${ }^{41}$. Puede decirse, pues, que Covarrubias, aun sin tener conocimientos él mismo de árabe, hizo una contribución notable al estudio del léxico español de este origen, y su influencia es perceptible hasta hoy en la literatura especializada.

\section{Bibliografía}

Ahumada Ignacio (2007), «Prólogo», en Guadix Diego de, Diccionario de arabismos. Recopilación de algunos nombres arábigos. Estudio preliminar y edición de M. Á. Moreno. Jaén, Universidad de Jaén, pp. XI-XVIII.

Alcalá Pedro de (1505), Vocabulista aráuigo en letra castellana. Granada.

Bajo Pérez Elena / Maíllo Salgado Felipe (2005), «Estudio introductorio», en: Guadix 2005: 19-131.

Alvar Ezquerra Manuel (2011), «El Tesoro de Sebastián de Covarrubias, primer diccionario monolingüe del español», en Académica. Boletín de la Real Academia Conquense de Artes y Letras, no 6, pp. 31-81.

Corominas Joan / Pascual José Antonio, Diccionario crítico etimológico castellano e hispánico. Madrid, Gredos, 1980-1991 [citado como DCECH].

Corriente Federico (1999), Diccionario de arabismos y voces afines en iberorromance. Madrid, Gredos.

- (2005), «Notas lingüísticas acerca de la Recopilación de algunos nombres arábigos de Diego de Guadix», en Estudios de Dialectología Norteafricana y Andalusi, no 9 , pp. 93-114.

Coseriu Eugenio (2000), «Andrés de Poza, lingüista del Renacimiento», en Actas de las II Jornadas de Onomástica, Bilbao, Real Academia de la Lengua Vasca I Euskaltzaindia, pp. 32-77.

Covarrubias y Horozco Sebastián de (1611), Tesoro de la lengua castellana o española, Madrid.

Crespo Juan (1992), «El arte diccionarista de Sebastián de Covarrubias», en ELUA, 8 , pp. 99-132.

Dozy Reinhart (1868), Glossaire des mots espagnols et portugais, dérivés de l'arabe. Leiden [2a ed.; $1^{\mathrm{a}}$ ed. de 1866].

41. El estudio crítico de la trayectoria lexicográfica de muchas voces permite extraer interesantes conclusiones para la historia de la lexicografía y la lexicología del español. Un ejemplo concreto podría ser la voz albahaca y su etimología a partir del ár. habaqah: la equivalencia semántica entre las dos formas fue descrita por primera vez en el Vocabulista de P. de Alcalá, obra a partir de la cual López de Velasco estableció la etimología que, entre otras, incluye Covarrubias en su Tesoro. De ahí pasa al Diccionario de autoridades, y por mediación de este, posteriormente al $D C E C H$. Covarrubias constituye, pues, a menudo un eslabón en una cadena de transmisión que enlaza obras elaboradas a lo largo de seis siglos. 
Eguílaz y Yanguas Leopoldo de (1886), Glosario etimológico de las palabras españolas (castellanas, catalanas, gallegas, mallorquinas, portuguesas, valencianas y bascongadas) de origen oriental (árabe, hebreo, malayo, persa y turco). Granada.

Guadix Diego de (2005 [c. 1593]), Recopilación de algunos nombres arábigos que los árabes pusieron a algunas ciudades y a otras muchas cosas. Edición, introducción, notas e índices de E. Bajo Pérez y F. Maíllo Salgado. Gijón, Trea.

López de Velasco Juan (1582), Orthographia, y pronunciación castellana. Burgos.

López Tamarid Francisco (1585), Compendio de algvnos vocablos arábigos introdvzidos en la lengua castellana en alguna manera corruptos, de que comúnmente usamos. Apéndice a A. de Nebrija, Diccionario de romance en latin. Granada.

Monroe James T. (1970), Islam and the Arabs in Spanish Scholarship (Sixteenth Century to the Present). Leiden, E. J. Brill.

Real Academia Española (1726-1739), Diccionario de la lengua castellana, en que se explica el verdadero sentido de las voces, su naturaleza y calidad, con las phrases o modos de hablar, los proverbios o refranes, y otras cosas convenientes al uso de la lengua. Madrid [cit. como Diccionario de autoridades].

Reyre Dominique (2006), "Prólogo segundo. Las llaves del Tesoro de Covarrubias», en Sebastián de Covarrubias, Tesoro de la lengua castellana o española, edición integral e ilustrada de Ignacio Arellano y Rafael Zafra. Madrid, Univ. de Navarra / Iberoamericana Vervuert, 2006, págs. L-LI.

Rodríguez Mediano Fernando / García-Arenal, Mercedes (2002), «Diego de Urrea y algún traductor más: en torno a las versiones de los "Plomos"”, en Al-Qantara, XXIII,2, pp. 499-516.

Ruhstaller Stefan (2012), «La Recopilación de algunos nombres arábigos de Diego de Guadix como temprano diccionario toponímico», en Vox Romanica, 71, pp. 163196.

Ruhstaller Stefan (2013), «Los inicios de la investigación sobre el arabismo léxico en español. El Compendio de Francisco López Tamarid frente a la Recopilación de Diego de Guadix», Bulletin Hispanique, 115,1, pp. 253-270.

Ruhstaller Stefan (2015), «Un aspecto poco investigado del Tesoro de la lengua castellana o española. La contribución de Covarrubias al estudio de los nombres de lugar», en Zeitschrift für romanische Philologie, 131 (2), pp. 326-354.

Seco Manuel (1988), "Covarrubias en la Academia», en Anales Cervantinos, 25/26, pp. 387-396. 
